\title{
Eminem Flertydige maskulinitetsdannelser mellem gangsterrap og mainstream ungdomskultur
}

Rapperen Eminem er et godt eksempel po̊, at maskulinitetsdannelse $i$ dag er en åben og flertydig proces. Han er en trendsattende mainstreamavantgardist, som via sine tekster viser flere maskuliniteter: Protestmaskulinitet, en kollektiv underklassemaskulinitet, hypermaskulinitet og metroseksualitet. Eminem er dermed en crossoverfigur mellem gangsterrappens sorte subkultur og popularkulturen.

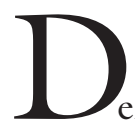

en amerikanske rapper Eminem (født 1972) er et synligt maskulint tegn i ungdomskulturen. Eminem er eksponent for gangsterrap, og han er en central medieaktør i populærkulturen. Han er interessant, fordi de maskuliniteter, han beskriver, er flertydige og omskiftelige, og fordi han er en hvid mand i en ellers traditionelt sort udtryksform - gangsterrappen. Gangsterrappen kendetegnes ved en positionering som en sort subkultur. Artiklen undersøger, hvordan Eminem gennem sine raptekster konstituerer maskuline subjektpositioner i forhold til etnicitet, klasse og relationer til det andet køn.

Artiklen tager udgangspunkt i Bronwyn Davies' (1999) poststrukturalistiske begreber, fordi de både formår at sige noget om en grundlæggende forståelse af virkeligheden, og fordi de giver konkrete bud på, hvordan man ved hjælp af diskursanalyse kan undersøge individets subjektiveringsproces. Diskurser har en konstituerende og reproducerende kraft, fordi de konstruerer 
mulige subjektpositioner for individet. Diskursanalysen kan ud fra folks aktive sprogbrug fortolke, hvordan de italesætter og positionerer sig selv i diskurserne. Sprogbrug forstås i denne sammenhæng bredt og inkluderer bl.a. sangtekster, billeder, tekster og udtalelser. Med diskursanalysens begreber er det centrale omdrejningspunkt, hvordan individer og diskurser gensidigt konstruerer og reproducerer kulturmønstre. I dette tilfælde undersøges Eminems balancering mellem gangsterrappens og mainstreams diskursive repertoirer, særligt set i forhold til de maskuline positioner han repræsenterer. Forståelsen af manderoller og maskuliniteter er inspireret af maskulinitetsforskeren R.W. Connell (2000). Connell illustrerer, at der findes flere sideløbende maskuliniteter og påpeger, at maskuline positioner er hierarkiske, dynamiske og modsætningsfyldte.

\section{GANGSTERRAPPENS NARRATIVER - SORT UNGDOMSKULTUR}

Gangsterrappen udspringer af et sort, maskulint arbejderklassemiljø i de amerikanske storbyer. Rap er som udgangspunkt en konkurrence mellem mandlige rappere om at være bedst til at rime, følge en rytme og fortælle historier. Gangsterrap er i sin oprindelige form mestendels sorte mænds fortællinger om livet i USA's ghettoer. Historierne skal umiddelbart virke autentiske og illustrere, at man har 'street credibility'. Gangsterrappens 'traditionelle' storylines fortæller om kulturelle stereotyper som gangsteren, hustleren og alfonsen - maskuline figurer som overlever i bander i de sorte ghettoer. Gangsterrappens narrativer er en blanding af ghettoromantisering, voldsforherligelse, våbenfetichisme, misogyni og en kritik af de sortes sociale og økonomiske vilkår. Rapperne italesætter også klasse, etnicitet og kønsrelaterede former for kulturel og politisk fremmedgørelse i mainstreamkulturens cirkler (Rose 1994). Rapperne er derfor både synlige kritikere og den stigmatiserede Anden i mainstreamkulturen. Mainstreamkultur forstås i denne sammenhæng ikke som en bestemt stil, men som et udtryk for alment genkendelig populær musik og stil kommunikeret gennem massemediernes kanaler, hvormed disse produkter ofte er produceret ud fra et ønske om massekonsum. Mainstream vil i takt med den musikalske udvikling xndre sig, f.eks. er dele af hip hoppen indfanget $i$ mainstream ligesom punk til tider afspejles $i$ moden. Alt efter ens kulturelle ståsted kan betegnelsen opfattes som positiv, neutral eller negativ (Dansk Kunstnerråd 2005). Gangsterrappen var ikke en del af mainstreamkulturen, før Eminem brød igennem i 1999 og sprængte de sidste barrierer i 2002 med årets bedst sælgende album. Rent musikalsk laver han også en genrecrossover til popmusikken, da han i sit gennembrudshit Stan har den kvindelig popsanger Dido til at synge omkvædet.

\section{EMINEMS SUBJEKTPOSITIONER}

Eminem bruger forskellige aliasser som rapper. Titlerne på Eminems CD'er illustrerer dette: 'The Slim Shady LP', 'The Marshall Mathers LP' og 'The Eminem Show'. Slim Shady, Eminem og Marshall Mathers repræsenterer tre subjektpositioner i Eminems tekstunivers, da de gennem forskellige kulturelle narrativer italesætter alternative maskuline positioner. Subjektpositioner forstås som 'et sted at tale fra', hvilket betyder, at individet reproducerer et diskursivt konstitueret narrativ for at blive anerkendt som subjekt. Et narrativ er naturaliserede, kulturelle fortællingsforløb, som står til rådighed som positioneringssmuligheder for de involverede subjekter (Davies 1999). Disse subjektpositioner indeholder både et begrebsmæssigt repertoire og en hierarkisk indplacering i diskursen, f.eks. positionen 'hvid mand' (Davies 2001). Positionering er relationel, idet man er afhængig af andres genkendelse og godkendelse af positionerne. Subjektpositionerne kon- 
strueres altså både diskursivt og interaktivt. De tre aliasser, som taler gennem rapteksterne, kan, når de opfattes som storylines, vise hvilke maskuline subjektpositioner Eminem, Slim Shady og Marshall Mathers (re-)præsenterer. I de efterfølgende afsnit vil de forskellige subjektpositioner uddybes.

\section{MARSHAL MATHERS:}

\section{STORYLINES FRA UNDERKLASSEN}

Marshall Mathers III er Eminems dåbsnavn. Gennem figuren Marshall beskriver Eminem en opvækst blandt underklassens fattige hvide og sorte. Marshall er også fortællingen om den hvide arbejdsløse mand, der ikke har nogen uddannelse, og som făr kone og barn i en tidlig alder.

I deserve respect / but I work a sweat for this worthless check /'bout to burst this tech, at somebody to reverse his debt / minimum wage got my adrenaline caged / full of venom and rage. (Eminem 1999: 9)

Marshall positioneres som en del af underklassen med en hård opvækst og mange nederlag, frustrationer og aggressioner. Marshall er en figur, hvor Eminem kan reflektere over livet som en del af underklassen og kritisere det samfund, som overser de fattige amerikanere. Marshall er således den stemme, som italesætter den fattige hvide mands vilkår og mulige subjektpositioner.

\section{SLIM SHADY:}

\section{UNDERKLASSENS ANTIHELT}

Subjektpositionen Slim Shady representerer et blodigt fiktivt univers, hvor storylines om den vrede, voldelige unge underklassemand fortxlles. Han siger alt det, som det politisk korrekte samfund ikke tillader.

you want me to fix-up lyrics while our president gets his dick sucked? / Fuck that. Take drugs. Rape sluts. / Make fun of gay clubs. (Eminem, 2000/b: 10)
Realismen og autenticiteten, som er et af rappens karakteristika, bliver her erstattet af et fantasiunivers, som er helt ude på ekstremernes overdrev.

touch this chainsaw, left his brains all / dangling from his neck while his head barely hangs on / blood, guts, guns, cuts

(Eminem, 2000/b: 11)

Slim er et negativt defineret portræt, som giver plads til fordomme og voldsfantasier.

\section{EMINEM:}

DEN VELARTIKULEREDE RAP-ARTIST

Subjektpositionen Eminem er den velartikulerede rapartist, som forener den reflekterede Marshall og den provokerende Slim.

This book is made by Slim Shady, from the mind of Marshall Mathers as seen from Eminem's point of view. (Eminem 2000/a: 3)

Eminem leger altså bevidst med forskellige figurer og viser, hvordan de er snoet ind $\mathrm{i}$ hinanden og tilsammen danner et multipelt selv. Eminem konstruerer et 'reality-show', hvor adskillelsen mellem virkelighed og figurer ophører, og hvor skellet mellem det private og offentlige er uklar. Eksempelvis rapper Eminem, at han vil slå sin kone, Kim, ihjel, samtidig med at deres skilsmisse bliver fulgt i diverse sladderblade. Eminem skaber derfor en tvivl hos lytteren om, hvor medie- og rapstjernen og figurerne adskilles, fordi grænsen mellem forfatter og det fortællende jeg udvandes. Rappen som genre påberåber sig autenticitet og biografisk status, men Eminem er tvetydig og tydeligt fiktiv. Dette betyder, at det kan være vanskeligt at skelne mellem forfatteren, fortælleren og figurerne. Denne analyse af Eminems maskuline positioneringer balancerer da også imellem at se på Eminem som 'virkelig' mediestjerne og på de tre aliasser, han præsenterer gennem sine raptekster.

Ifølge Davies skabes og reproduceres 
subjektet konstant gennem de forskellige sociale interaktioner, det deltager i. Individet har derfor ikke en stabil og fikseret identitet, men påvirkes konstant af ydre forhold og sociale relationer. Dette behøver ikke betyde, at individet opfatter sig selv som et fragmenteret subjekt. Individet repeterer en kulturelt genkendelig position $\mathrm{i}$ diskursen for at blive genkendt og anerkendt som subjekt (Davies 2001, Butler 1993). Eminem illustrerer ved hjælp af sine aliasser nutidens fleksible og tvetydige subjektiveringsproces, hvor den position, man indtager, er afhængig af, hvilken interaktion man deltager $i$.

\section{KuLTURELLE STEREOTYPER OG KULTUREL GENKENDELIGHED}

Ifølge Davies bruger vi kulturelle stereotyper som ressourcer til at spejle vores agerede subjektpositioner i. Stereotyper udtrykker en given tids sociale, politiske og kulturelle forestillinger (Sernhede 1995). En kulturel stereotyp kan f.eks. være 'sort gangsterrapper' og forestillingen om denne positions handlemuligheder i den konkrete relation. Subjektpositioner er dermed både en social fortolkning og en forhandling, der sker i den sociale interaktion. Fra et poststrukturalistisk synspunkt er virkelige og fiktive historier, vi hører, læser og observerer derfor med til at konstruere en række storylines eller narrativer, som kan danne baggrund for vores positioneringsstrategier (Davies 1999). Individet ønsker som regel at blive accepteret indenfor kulturen. Derfor indtager individet nogle kulturelt genkendelige subjektpositioner, ellers vil han skubbes ud i periferien af kulturen og blive ignoreret som subjekt (Davies 1999, Søndergaard 2000). Positionering fremstilles altså som en form for kamp, både om retten til at tale ud fra en særlig synsvinkel og retten til at positionere sig selv og andre. Eminems favntag med kulturelle stereotyper identificeres i de kommende afsnit.

\section{'THE BLACK MACHO' KONTRA 'WHITE TRASH'}

Gangsterrappens tekster er ofte storylines om 'the black macho'. Denne kulturelle stereotyp afspejler den sorte arbejderklasses maskulinitetskonstruktioner, hvor manden dominerer over kvinden, hvor der er indbyrdes konkurrence mellem mænd, aggressiv social adfærd og en legitimeret dobbeltmoral i relation til kvinden (Sernhede 2002). Der findes også andre tendenser i hip hop kulturen, men i forhold til gangsterrappen illustrerer 'the black macho' nogle diskursive praksisser, som bruges til at opnå autenticitet gennem en reference til romantiserede antihelte som f.eks. bandemedlemmer i ghettoernes maskuline gadeliv. 'The black macho' er en etnificeret Anden, der fremstår som primitiv, eksotisk, kriminel og potent (Sernhede 1995) og dermed overdrevet maskulin eller hypermaskulin. Hypermaskulinitet udvikles ofte ud fra maskuline stereotyper som gangsteren og hustleren og bekræfter kønsstereotyper i behovet for at skabe mandlige forbilleder. Dette kan tolkes som en kompensation for egen maskulin usikkerhed (Sernhede 1995). De nære maskuline forbilleder, som f.eks. fædre og brødre, i de amerikanske ghettoer, er typisk fraværende på grund af fængselsophold og splittede familier (George 1998). Italesættelsen af stereotype kønspositioner bliver i gangsterrappen ofte en fejring og synliggørelse af Andetheden.

Black male pride is a weapon and an attitude. It is an attack on the negative and it is a way to spin the negative on its head.

(George 1998: 50)

Eminem fremstår som den hvide outsider, der opnår accept i en traditionel sort musikkultur. Han er f.eks. den første hvide rapper, der har været på forsiden af det anerkendte sorte hip hop magasin "the Source” (Jakobsen 2003). Eminem opnår 'street credibility', fordi han repræsenterer en hvid mand, opvokset i en fattig, sort for- 
stad til Detroit. Han beskriver sig selv som en 'angry blonde' og behandler i flere tekster etnicitet.

Now don't ignore me, you won't avoid me / you can't miss me, I'm white, blonde-haired and my nose is pointy. (Eminem, 2000/b: l)

Han er blevet anklaget for at stjæle de sortes musik, ligesom Elvis Presley i sin tid mødte de samme beskyldninger. Eminem beskriver selv sin musik således:

I don't do black music, I don't do white music / I make fight music for high-school kids. (Eminem, 2000/b: 10)

Citatet illustrerer, at der er en kamp om retten til at udtrykke sig gennem rap. Kampen har en etnisk vinkel, hvor de sorte dominerer udtryksformen. Eminem forsøger at skabe en diskurs, hvor rappen ikke kun er de sortes musik, men tilhører unge uanset etnicitet, og søger hermed at skabe en position, hvor han ikke bliver ekskluderet som et kulturelt uigenkendeligt subjekt.

Selvom vi lever i et multikulturelt samfund, italesætter hvide kun undtagelsesvist spørgsmålet om egen etnicitet fordi de sjældent oplever diskrimination (Frosh 2002). Rappen som genre er etnicitetsbåren, og Eminem er derfor nødt til at italesætte etnicitet, hvilket f.eks. kommer til udtryk når, han kalder sig selv 'angry blonde' og 'white trash'. Eminem positionerer sig som en ikke-dominerende hvid, som 'white trash', altså hvid, fattig underklasse. Dermed kan han identificere sig med og bruge en sort musikkultur som gangsterrappen, selvom det primært er den sorte underklasses musik. Han sidestiller altså fattige hvide med fattige sorte, og derfor bliver Eminems tilgang til at kunne bruge rap således mere et spørgsmål om klassesamhørighed frem for et etnicitetstilhør.
EMINEMS TVETYDIGE BRUG AF GANSTERRAPPENS 'BLACK MACHO' STORYLINES

I gangsterrappen er fascinationen af vold, våben og maskulin selvhævdelse central. Man blærer sig med sine våben, penge, biler, smykker og kvinder (Sernhede 1995, 2002). Positionen Slim Shady repræsenterer også 'traditionelle' gangsterrap-temaer såsom mord, våben og kriminalitet, men Slims storylines udtrykker såvel fascination som ironi i forhold til disse temaer. Han er inspireret af film og tegneserier, hvilket resulterer $\mathrm{i}$, at nogle af fortællingerne får en overdrevet og fiktiv karakter.

Windows tinted on my ride when I drive in it / So when I rob a bank, run out and just dive in it ...Die, bitches, bastards, brats, pets / This puppy's lucky I didn't blast his ass yet / If I ever gave a fuck, I'd shave my nuts / tuck my dick in between my legs and cluck / ...Shit, half the shit I say, I just make it up / To make you mad so kiss my white naked ass. (Eminem, 2000/b: 1)

Eminem nærmer sig en kompensatorisk hypermaskulinitet med denne storyline, men på den anden side er hele billedet af og sprogbruget i forhold til denne gangsterstereotyp ironisk og humoristisk. Gangsterstereotypen brydes f.eks. ved, at figuren fremstår som kvinde/transvestit og dekonstrueres atter af metakommentaren om, at han digter. Eminem bruger disse storylines til provokation og sarkasme. Han romantiserer ikke over ghettolivet, men ironiserer over gangsterrappen og tager dermed afstand fra selve det fundament, hans tekster hviler på. Eminem er altså en konstant tvetydig figur, som bruger traditionelle gangsterrap storylines i en blanding af humor, ironi og fiktion.

Der hvor Eminem er tro mod gangsterrappen, er i kritikken af samfundet og middelklassen. "Gangsta rap, in particular, does its best to turn liberal middle-class morality on its head. It is deliberately foul-mouthed, 
deliberately offensive" (Shaw 2000: 45). Eminem bruger dog gangsterrappens kritik af samfundet og den åbenlyse provokation $\mathrm{i}$ et andet tematisk forløb end andre gangsterrappere. Eminem fortæller via Marshall om selvhad og håbløse baggrunde i stedet for at prale med og romantisere over det maskuline ghettogangsterliv.

Wore spectacles with taped frames and a freckled nose / a corny lookin' white boy, scrawny and always ornery $[\ldots]$ I was harassed daily by this fat kid.

(Eminem 2000 b: 8)

Når Eminem som hvid gør brug af en sort udtryksform, ironiserer over 'the black macho'-stereotypen, og italesætter 'white trash', synliggør han etniciteternes diskursive konstruktion og de etnisk maskuline stereotyper og hierarkier.

\section{ProtestMaskULINITET - MIDDELKLASSE KONTRA \\ ARBEJDERKLASSE}

Eminem er blevet anklaget for diskrimination, homofobi, voldsforherligelse, misogyni og fordærvelse af de unge (Lykkeberg 2003, Juul Jensen 2003).

Quit tryin' to censor music. This is for your kids amusement / But don't blame me when little Eric jumps off of the terrace / you should've been watching him. Apparently you ain't parents. (Eminem 2000/b: 10)

Eminems subjektposition i relation til offentligheden er den synlige outsider, der dekonstruerer samfundets reproducerende positioner. Eminem er den marginaliserede, som repræsenterer den hvide underklasse i USA og provokerer offentligheden til at synliggøre hans positioneringsstrategier. I denne subjektposition viser Eminem en protestmaskulinitet i sin kritik af samfundet. Protestmaskuliniteten bruger aggressioner og vold som strategier til at få en hørbar stemme i de dominerende diskurser. Den udspiller sig som en hård protest mod alt det, som der ikke er ligeværdig adgang til. Derfor bliver livet på kanten af loven en del af protesten mod det etablerede system (Sernhede 2002).

Whatever happend to whylin' out and bein' violent / whatever happened to catchin' a good'ol' fashioned/ passionate ass-whoopin' (Eminem 2000/b: 15).

Protestmaskuliniteten er altså ligesom hypermaskuliniteten en reaktion på marginalisering og magtesløshed og repræsenteres af Slim og Eminems positioneringer.

Eminems storylines besidder en 'street wiseness', hvor han rapper om den urbane dagligdag, som forstædernes middelklasse sjældent kommer i nærheden af. Han kan derfor forstås som et talerør for de dele af samfundet, som ikke kan begå sig i de akademiske diskurser, og han er kilde til et reflekteret bud på magtforhold og sociale vilkår fra andre udgangspunkter end det akademiske (Sernhede 2002).

\section{RELATIONER TIL KVINDEN -}

\section{'Moderen' OG 'ÆGTEFÆLlen'}

Eminem skaber forskellige storylines om forholdet mellem mand og kvinde. Her analyseres hans positioneringer i forhold til kvindelige stereotyper som 'moderen' og 'xgtefallen'. I relationen mellem mor og søn skaber Eminem gennem Marshall en storyline om en opløst familie. Marshall anklager moren for omsorgssvigt og stofmisbrug og positionerer hende som en dårlig mor og et dårligt forbillede.

When I was just a little baby boy my mamma used to tell me these crazy things / She used to tell me my daddy was an evil man, she used to tell me he hated me / but when I got a little bit older and I realized she was the crazy one. (Eminem 2000/b: 11) 
Moren har dog været en central normgivende faktor i hans liv, fordi der ikke har været en far eller andre nære mandlige rollemodeller. Faren er totalt fraværende i teksterne, og 'sønnen' kompenserer for dette ved at finde maskuline forbilleder andetsteds, f.eks. i film. Marshall sammenligner sig selv med en ung Clint Eastwood (Eminem 2000/b: 10). Den unge Eastwood er kendt for sine Western- og Dirty Harryfilm, hvor han er den tavse, ensomme helt med stenansigt, der klarer problemerne ved hjælp af sine trofaste hjælpere, hesten og seksløberen.

Eastwood also develops a kind of dead-pan humour[...] The idea seems to be here that in the face of catastrophe, while other men and women are freaking out, the hero spits, gazes at life untroubled, and finally makes a gnomic comment. (Horrocks 1995: 75)

Eminem iscenesætter sønnen som den ensomme, ufrivillige helt, som er 'tough', kold og rolig. Ligesom 'the black macho' er 'den ensomme helt' endnu en hypermaskulin stereotyp. Marhalls forhold til sit eget køn er altså præget af ambivalens, hvor der både findes et negativt, usikkert billede af manden og idealiserede maskuline forbilleder fra fiktionens verden. Dette viser ydergrænserne for de maskulinitetspositioner, Eminem skaber, hvor der skal balanceres mellem 'den ensomme helt' og den fraværende far som de yderste poler.

Eminem tager også relationen mellem xgtemand og kone op. I flere af teksterne slår hovedpersonen 'Kim' ihjel. Kim er navnet på Eminems virkelige kone.

Oh what's a matter Kim? / am I too loud for you? / too bad bitch, your gonna finally hear me out this time $[\ldots]$ why do you always make me shout at you? / how could you? / just leave me and love him out the blue. (Eminem 2000/b: 13)

Teksten Kim viser mandens desperation og magtesløshed overfor kvinden som den Anden og den hypermaskuline positions fastlåsthed, hvor følelsestilkendegivelse ikke er en del af det diskursive repertoire. Kvinden har ingen stemme, hun er den usynliggjorte Anden, som udelukkende er til stede som objekt. Denne mandetype har vanskeligt ved at finde en stemme i den heteroseksuelle kærlighedsrelation og dermed konstruere sin egen position i denne relation. Eminems tekster kan også tolkes som en kritik af denne mandetype.

Bitch, I'm-a kill you! Like a murder weapon I'm-a conceal you / in a closet with mildew, sheets, pillows and film you [...] ha, ha, ha I'm just playin' ladies, you know I love you. (Eminem 2000/b: 11)

Historierne er altså også ironiske, dekonstruerende fortællinger om den hypermaskuline stereotyp. Det er derved ikke forfatterens liv, der offentliggøres. Derimod skabes der fortællinger om mandlige kulturelle stereotyper, som f.eks. den ensomme helt og den hypermaskuline machomand.

\section{SKÆRINGSFELTER MELLEM}

\section{SUBKULTURELLE OG MAINSTREAM} MANDEROLLER

Eminem formidler ikke kun musik til mainstream, men repræsenterer også en hel række attituder og holdninger via de forskellige subjektpositioner. Gangsterrappen, som genre og livsstil, er som sagt kendt for at være pralende og selvhøjtidelig samt eksponere en hypermaskulin selviscenesættelse, hvor manden har et diskriminerende syn på homoseksuelle og kvinder, og er fascineret af våben, vold og kriminalitet. Denne gangsterlivsstil har Eminem en tvetydig position i forhold til, fordi han ironiserer over den, men samtidig iscenesætter han sig også som en del af genren. Han praler med sit talent som rapper og udmaler, hvordan han vil myrde de folk omkring sig, som kritiserer og irriterer ham. 
All I see is sissies in magazines smiling / whatever happened to whylin' out and bein' violent. (Eminem, 2000/b: 15)

Etniciteten har også en betydning for Eminems position i mainstream. Han bliver bindeleddet mellem en sort subkultur og en mainstreamkultur, idet han er en musikalsk og tematisk hybrid. Når en hvid mand italesætter 'the black macho', kommer der fokus på de forskellige etniciteters forvaltning af maskulinitet, og stereotyperne tydeliggøres. Samtidig viser han en marginaliseret hvid maskulin position, 'white trash', og den hvide trækkes derved ud af en naturaliseret, hegemonisk subjektposition. Eminem reproducerer og dekonstruerer altså flere etniske diskurser i ungdomskulturens centrale medier, som f.eks. MTV.

I populærkulturen er der dukket nye maskulinitetsbetegnelser op, hvilket kunne tolkes som et tegn på, at der kæmpes om at definere den hegemoniske maskulinitet. Man taler ligefrem om en ny mandetype: 'Den metroseksuelle mand' (Tougaard 2004). Det er en narcissistisk form for maskulinitet, som passer ind i vores æstetiserede hverdag, hvor selvoptagethed, selvbevidsthed og medieberømmelse er centrale for maskulinitetskonstruktionen (Simpson 2004). Eminem er udråbt til en metroseksuel mand af begrebets skaber, den engelske forfatter Mark Simpson:

And yet Em (Eminem), who like Beckham can't resist a big fat shiny lens, who loves to pose half-naked (and drag it up in his videos), and who also wears his children as accessories, is clearly and alarmingly metrosexual himself.

(Simpson 2002: 17)

Eminem er vanskelig at kategorisere entydigt, og han repræsenterer ikke nær så tydelig en metroseksualitet, som f.eks. David Beckham. Eminem er en brobygger, som forener flere maskuliniteter. Han præsenterer både rebellen, den hypermaskuline og den metroseksuelle subjektposition. Han er en slags mainstreamavantgardist, som forener metroseksualitet med en subkulturel maskulinitet, og han formår at få eksponeret dette i mainstream mediecirkler. Dette giver et noget flertydigt billede af manderollen, men på den anden side viser det også, hvilke muligheder nutiden giver individet, fordi man kan skifte imellem forskellige og modsatrettede maskuliniteter (Connell 2000).

En del af de karakteristika, som Simpson (2002) betegner som Eminems metroseksualitet, vækker dog også genklang i gangsterrappens diskursive praksisser. De ting, som karakteriserer en metroseksuel, har imidlertid helt andre konnotationer i gangsterrappen. Kropsfikseringen, tøj, smykker, biler og kvinder er en del af gangsterens statusskabende objekter. Gangsterrapperne efterligner ghettoernes helte: Gangsteren, hustleren og alfonsen i deres stil. Den hårdt trænede krop, dyrt tøj, guldsmykker, stylede biler samt smukke kvinder er en del af gangsterens måde at vise succes og stil på. I hip hoppen har disse ting derfor ikke noget med narcissisme og velvære at gøre. Tingene er statussymboler og del af en machokultur.

Eminem er altså en 'crossoverfigur' mellem hip hoppens og mainstreams forskellige maskulinitetstyper. På den måde dukker der et mangefacetteret og modstridende billede op af nutidens maskuline subjektpositioner. Eminem er en af eksponenterne i mainstream for at maskulinitet kan være multipelt, og at selvet kan indeholde modstridende diskursive praksisser.

\section{"I AM WHATEVER YOU SAY I AM"}

Eminem viser en 'white trash' position, som placerer sig imellem en eksklusion fra den hvide middelklasse og en tilnærmelse til eller delvis identifikation med det sorte ghettoliv. I denne position skabes der en mainstreamavantgarde, som viser flere maskuliniteter: Protestmaskulinitet, en kollektiv underklassemaskulinitet, hypermaskuli- 
nitet og metroseksualitet. Eminem er dermed et bindeled mellem gangsterrappens sorte subkultur og dele af mainstreamkulturen. Han er en tvetydig figur som både demonstrerer en hypermaskulin ghettogangster, men samtidig indtager en ironisk distance til denne kulturelle stereotyp. Ved hjælp af sit musikalske udtryk, som tager udgangspunkt i gangsterrappen, og provokerende tekstindhold, formår han at gøre en normalt marginaliseret position synlig $i$ den dominerende populærkultur samt stille spørgsmålstegn ved kulturens diskursive praksisser. De subjektpositioner, han eksponerer i mainstream, er både marginale og centrale, fordi han făr ekstrem opmærksomhed som fokuseret forbillede og mediestar, og samtidig formår at fortælle kulturelle storylines om den fattige, hvide, marginaliserede maskulinitet via figuren Marshall Mathers. Selvet kommer til udtryk i samspillet mellem etnicitet, klasse og køn, hvor Eminem dekonstruerer sorte og hvide diskursive praksisser samt kritiserer de dominerende diskursers brug af klasse- og kønsstereotyper. Eminem kombinerer gangsterrappens hårdkogte, direkte macho-stil med et fiktivt univers, hvor gangsterrappernes voldsfascination, misogyni, homofobi og homosociale frellesskaber overdrives til det ekstreme gennem figuren Slim Shady.

Kompleksiteten ved de forskellige subjektpositioner viser sig også i forhold til kønnet. De maskuline idealer findes i helteskikkelser fra film, hvorimod de nære mandlige forbilleder er fraværende. Forholdet til eget køn skabes altså imellem disse poler, og der udvises en hypermaskulinitet, der kompenserer for grundlæggende usikkerhed og følelse af samfundsmæssig marginalisering gennem figuren Marshall Mathers. Forholdet til kvinden er vanskeligt, idet denne maskuline position ikke har følelsestilkendegivelse som et diskursivt repertoire. Eminem forbinder altså flere maskuline positioner og viser dermed selvets modsigelsesfulde subjektiveringsproces. Det er ikke Eminems virkelige selv, der eks- poneres. Sangene er storylines med kulturelle figurer, og dermed er teksterne en forfatters konstruktion af forskellige maskuline positioneringsmuligheder i ungdomskulturen. Eminem formidler altså en poststrukturalistisk fortællestemme, hvor figurerne unddrager sig et stabilt selv. Eminem iscenesætter en multipel figur, der indeholder modstridende maskuliniteter, hvilket medvirker til at illustrere den komplekse og paradoksale subjektiveringsproces i senmoderne ungdomskultur.

\section{LITTERATUR}

- Butler, Judith (1993): Bodies that Matter - on the Discursive Limits of "Sex". Routledge, London. - Connell, R. W. (2000): The men and the boys. Polity, Cambridge.

- Dansk Kunstnerråd (2005): Debat om Mainstream - Notater fra Kunstpolitisk Forum 2005. Dansk Kunstnerråd, København.

- Davies, Bronwyn; Harré, Rom (2001): Positioning: The Discursive Production of Selves, i Wetherell, Margaret; Taylor, Stephanie \& Yates, Simeon J. (eds.) Discourse Theory and Practice. Sage, London.

- Davies, Bronwyn (1999): A body of writing 19901999. Altamira Press, Walnut Creek.

- Eminem (2000/a): Angry blonde. Harper Collins Publishers inc., New York.

- Eminem (2000/b): The Marshall Mathers LP. Interscope, Aftermath.

- Eminem (1999): The Slim Shady Lp. Interscope, Aftermath.

- Frosh, Stephen; Phoenix, Ann \& Pattman, Rob (2002): Young Masculinities - Understanding Boys in Contemporary Society. Palgrave, Hampshire.

- George, Nelson (1998): Hip Hop America. Penguin Books, New York.

- Horrocks, Roger (1995): Male Myths and Icons Masculinity in Popular Culture. Macmillan Press Ltd, London.

- Jakobsen, Joakim (2003): Eminoritet: Infam. Weekendavisen, 17/01/2003. Lokaliseret i Infomedia $17 / 01 / 2003$.

- Juul Jensen, Jesper (2003): Til fest med fjenden. Information, 12/12/2003. Lokaliseret i Infomedia $12 / 12 / 2003$.

- Lykkeberg, Rune (2003): Hvem synes han er genial? Information, 12/12/2003. Lokaliseret i Infomedia $12 / 12 / 2003$. 
- Rose, Tricia (1994): Black Noise - Rap Music and Black Culture in Contemporary America. Weslyan University Press, New England.

- Shaw, William (2000): Westsiders - stories of the boys in the hood. Bloomsbury, London.

- Sernhede, Ove (2002): AlieNation is My Nation - Hiphop och unga mäns utanförskap i Det Nya Sverige. Ordfront förlag, Stockholm.

- Sernhede, Ove (1995): Modernitet, adolescens och kulturella uttryck. Göteborgs Universitet, Göteborg.

- Simpson, Mark (2004): Metrodaddy Speaks! Lokaliseret 02/03/2004 på: http://www.marksimpson.com/pages/journalism/metrodaddyspeaks.html.

- Simpson, Mark (2002): Meet the Metrosexual: Hollywoods New Love Affair. Lokaliseret 02/03/ 2004 på: http://archive.salon.com/ent/feature $/ 2002 / 07 / 22 /$ metrosexual/indes $2 / \mathrm{html}$. - Søndergaard, Dorte Marie (2000): Kønnet subjektivering, i Kvinder, Kon og Forskning, 2000/1. - Tougaard, Helle og Carlsen, Jette Meier (2004): Mrnd i nye roller. Jyllandsposten, 22/02/2004. Lokaliseret i Infomedia 22/02/2004.

\section{SUMMARY}

Multiple masculinity for mations among gangster rap and mainstream youth culture The article is about the white rapper Eminem and the way he constructs masculinities. The article is based on feminist, poststructuralist theory. It concentrates on Bronwyn Davies approach to discourse analysis. Davies develops concepts that describe the process of subjectification. The main concept is 'positioning' understood as the discursive production of culturally intelligible selves. The findings of the analysis are that Eminem is developing a multiple, fictive self where ethnicity, class and masculinity intersect fluently and differently depending on the social interaction. Using stereotypes, often with irony, Eminem is telling stories about the white trash youth in America and uses byper masculinity, protest masculinity, metro sexuality, black macho and white trash storylines. He is also making a reflective critique of the youth media of today.

Rikke Møller, cand.mag. i kultur og formidling Sundheds- og kulturformidler i Sundhedshus for unge, Århus Kommune. 
Brevene

Efter min død blev det, da jeg ikke efterlod mig nogen pårorende, fagfolks opgave at gore mit bo op.

Mine malerier, tegninger og grafik og mine mange skitseboger blev gemt. Mens det blev besluttet at brande nogle af mine private breve. 